\title{
Características dos Médicos Plantonistas das Emergências de Salvador
}

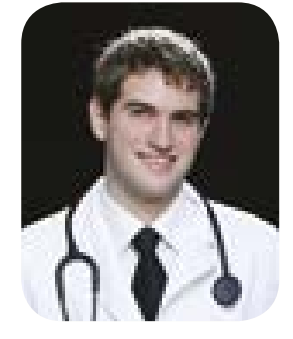

\author{
Marcelo Kirschbaum¹, Gilson S. Feitosa-Filho ${ }^{1}$
}

Artigo original publicado em Characteristics of training and motivation of physicians working in emergency medicine. Gilson Soares Feitosa-Filho, Marcelo Kirschbaum, Yuri Costa Sarno Neves, et al. Rev. Assoc. Med. Bras., 63 (2), 112-7.

Palavra-chaves: medicina de emergência; motivação; suporte avançado de vida em cardiologia Keywords: emergency medicine; motivation; advanced cardiovascular life support

\section{INTRODUÇÃO}

A medicina de emergência é uma área de atuação que requer decisões rápidas, às vezes imediatas. Para que intervenções corretas sejam realizadas em pouco tempo é fundamental a atuação de uma equipe médica bem treinada e motivada.

A capacitação técnica é resultante da combinação da experiência profissional associada ao treinamento adquirido na graduação, residência médica e cursos de imersão focados na medicina de emergência.

Os dados na literatura científica em relação ao perfil dos profissionais que trabalhem com medicina de emergência no Brasil são escassos.

\section{OBJETIVO}

Definir o perfil dos médicos que trabalham em prontos-socorros de médio e grande porte em Salvador, Bahia, em relação ao treinamento profissional, motivação e expectativas a respeito do futuro profissional.

\section{MÉTODOS}

Estudo de corte transversal realizado entre janeiro e março de 2012, no qual um questionário confeccionado pelos pesquisadores foi aplicado pessoalmente em aproximadamente $75 \%$ dos médicos plantonistas dos prontos-socorros de 24 dos 25 hospitais de médio e grande porte de salvador, públicos e privados (apenas um hospital negou-se a participar do estudo).

Neste questionário constavam perguntas acerca da formação dos indivíduos, graduação e pós-graduação, especialização, cursos de imersão em urgência e emergência, satisfação pessoal no trabalho em pronto-socorro e objetivos a longo prazo em relação a esse trabalho.

\section{RESULTADOS}

Seiscentos e cinquenta e nove médicos foram entrevistados em hospitais públicos, privados e públicos/ privados de Salvador/BA. A idade mediana dos entrevistados foi 34 anos, sem predominância de gênero. Dentre os entrevistados, $14,6 \%$ estavam cursando alguma residência médica e estavam realizando plantões por fora da residência. Cerca de metade $(50,7 \%)$ dos médicos referiu ter título de especialista.

Respectivamente, $5,2 \%, 18,4 \%$ e $11 \%$ dos médicos declararam ter realizado cursos de BLS, ACLS e ATLS nos últimos dois anos que precederam o estudo. Os médicos mais jovens tinham uma maior participação no curso de ACLS.

Dentre as razões para trabalhar com urgência e emergência, $41,7 \%$ dos entrevistados disseram que gostam da atividade. A despeito disso, apenas 13,1\% destes profissionais referiram estar plenamente satisfeitos com o trabalho no setor e $81,3 \%$ disseram pretender parar de trabalhar neste setor nos próximos 15 anos. A mediana de anos que os entrevistados pretendem parar suas atividades em pronto-socorro foi de 5 anos.

Houve uma relação positiva entre ter realizado residência médica e considerar ter uma performance excelente na atividade exercida. Também houve correlação entre satisfação com o trabalho e autoavaliação positiva.

Os principais motivos citados para pretender parar de trabalhar em emergência nos próximos 15 anos foram "estresse no ambiente de trabalho" e "condições inapropriadas de trabalho".

Tabela 1- Principais motivos para trabalhar nos serviços de emergência

\begin{tabular}{ll}
\hline \hline Motivo & $\mathrm{n}=659$ \\
\hline Gostar da atividade & $270(41.7 \%)$ \\
\hline Oportunidade de trabalho & $145(22.4 \%)$ \\
Bom ganho financeiro & $137(21.2 \%)$ \\
Necessidade de ganhar experiência & $63(9.7 \%)$ \\
Outras razões & $32(4.9 \%)$ \\
Não respondeu & $12(1.8 \%)$ \\
\hline \hline
\end{tabular}


Tabela 2- Frequência de médicos certificados nos principais cursos de imersão em medicina de emergência nos últimos dois anos, classificados de acordo com a idade.

\begin{tabular}{cccc}
\hline \hline Curso & $<34$ anos $(\mathrm{n}=311)$ & $\geq 34$ anos $(\mathrm{n}=345)$ & $\mathrm{P}$ \\
ACLS & $73(23.6 \%)$ & $48(13.9 \%)$ & 0.001 \\
ATLS & $37(12.0 \%)$ & $35(10.1 \%)$ & 0.456 \\
BLS & $19(6.1 \%)$ & $15(4.3 \%)$ & 0.300 \\
\hline \hline
\end{tabular}

\section{CONCLUSÃO}

Os médicos que trabalham nos serviços de emergência dos hospitais de grande e médio porte de Salvador são preponderantemente jovens, com pouco treinamento em cursos de imersão e com necessidade de maior motivação para esta atividade.

\section{COMENTÁRIOS}

A realidade do mercado de trabalho médico atualmente faz com que o médico recém-formado inicie sua carreira trabalhando em plantões avulsos de urgência e emergência. Assim, predominam neste setor do hospital profissionais ainda com pouca experiência.

Dificilmente um profissional segue carreira nesta área de atuação e os motivos parecem óbvios: além do excessivo desgaste próprio desta atividade, não há um adequado reconhecimento e, além disso, por vezes as condições de trabalho são ruins.

O resultado do presente estudo corrobora com essa hipótese, demonstrando que há um predomínio de médicos inexperientes e pouco motivados em seguir carreiras nos prontos-socorros. Este problema traz um paradoxo, já que é justamente nas emergências onde preparo e experiência são necessários para as tomadas de atitudes corretas com velocidade. Acreditamos que a luta por uma melhor capacitação técnica desses profissionais deva ser uma constante, além da melhora das condições de trabalho, como forma de estímulo para melhorar a satisfação do profissional emergencista.

Um fato curioso que precisa ser mencionado sobre este estudo é que o mesmo foi realizado em 2012, antes que fatos políticos de 2013 tornassem ainda mais turbulenta a ação dos médicos em emergências. É opinião de ambos os autores que se talvez a pesquisa tivesse sido realizada mais recentemente, a questão da motivação pudesse ser ainda menor.

Também é importante notar, como resultante da dinâmica da economia do nosso país, que alguns destes hospitais incluídos no presente estudo fecharam as portas ou reduziram sua atuação no SUS, o que talvez faça com que os dados apresentados não reflitam fielmente a prática das emergências atuais.

Por fim, digno de nota, é que a atuação de um centro de cursos de imersão, chamado INESS, vinculado à $\mathrm{ABM}$ e situado na Pupileira, nestes últimos anos, aumentou muito a oferta de cursos de imersão ao médico baiano e, assim, possivelmente, o número de emergencistas atuais, treinados um pouco melhor que os vistos em 2012.

A realização de uma pesquisa como esta não é fácil. $\mathrm{O}$ alvo dos questionários frequentemente é pré ou pós-plantão, e com pressa. Fazia-se necessário percorrer in locum todos os hospitais em diversas trocas de plantão, em 2 turnos do dia. Isso não seria possível sem a colaboração de 2 grupos de estudantes muito especiais e determinados: o GEPEC (Grupo de Estudos e Pesquisas em Cardiologia) e a LAEC (Liga Acadêmica de Emergências Clínicas). A LAEC é uma ativa Liga Acadêmica da Escola Bahiana de Medicina, à época presidida pela Ac. Camila Kruschewsky Falcão. Já o GEPEC é um grupo criado pelo Prof. Gilson Feitosa-Filho, onde orienta estudantes selecionados de quaisquer faculdades de medicina de Salvador. Este grupo segue renovando-se, em ampla atividade, desenvolvendo novos estudos e pesquisas, inclusive recentemente premiadas em congresso de cardiologia.

\section{REFERÊNCIA}

1. Characteristics of training and motivation of physicians working in emergency medicine. Gilson Soares Feitosa-Filho, Marcelo Kirschbaum, Yuri Costa Sarno Neves, Bruna Melo Coelho Loureiro, Victor Augusto Camarinha de Castro Lima, Rafael Marques Calazans, Camila Kruschewsky Falcão, Renata Trindade El Fahl, Bianca Recarey Barreto.Rev. Assoc. Med. Bras., 63 (2), 112-7.

\section{1- Serviço de Cardiologia Clínica do HSI \\ Endereço para correspondência: marcelo.kirschbaum@gmail.com}

